\title{
«PARECIÓ SER COSA HECHA POR MANO DE LA DIVINA PROVIDENCIA»: EL DISCURSO PROVIDENCIALISTA, UN CASO DE CONTINUIDAD Y DESVÍO DESDE LA CRÓNICA REAL A LA INDIANA
}

\author{
Cinthia María HaMLin \\ Universidad de Buenos Aires - SECRIT
}

«El dedo de Dios va marcando jornadas tristes al lado de días gloriosos. La red de providencialismo lo encierra todo» Cepeda Adán ${ }^{1}$

Si bien el providencialismo tiñe la producción historiográfica castellana desde los tiempos en los que Paulo Orosio llevó a esas tierras la concepción agustiniana de la Ciudad de Dios, será con los Reyes Católicos que este tipo de discurso llegue a su máximo esplendor. «Lo encierra todo», en palabras de Cepeda Adán. Heredera de toda la tradición historiográfica previa, la historiografía indiana que emerge justo en este período difícilmente pueda sustraerse de esta característica.

Sin la pretensión de abarcar toda la problemática concerniente a la relación entre la cronística medieval y la indiana, nos disponemos a hacer una pequeña contribución con el estudio de tres casos particulares que tal vez la iluminen. Nos centraremos, pues, en el análisis del discurso providencialista y sus usos en las Memorias del Reinado de los Reyes católicos para ver cómo esta «imposición de un designio unificado del pasado y del presente», en términos de Tate $^{2}$, es la que determina todas las estrategias narrativas y la elección aparentemente azarosa -0 memoriosa- de la materia narrada. Luego analizaremos cómo este punto de vista historiográfico varía en un episodio -en La Crónica de los Reyes Católicos de Pulgar-variación que se manifiesta como una de las primeras documentaciones de lo que sucederá más adelante con Las Casas.

\footnotetext{
${ }^{1}$ José Cepeda Adán, «El providencialismo en los cronistas de los Reyes Católicos», en Arbor, 17 (1950), p. 181.

${ }^{2}$ Robert B. Tate, «La Historiografía en la España del siglo XV», en Ensayos sobre historiografía peninsular del siglo XV, Madrid, Gredos, 1970, pp. 280-296, cita en p. 295.
} 


\section{Las Memorias en el seno de la tradición historiográfica: novedad y objetivo}

Andrés Bernáldez escribe sus Memorias entre 1504 y $1513^{3}$, período que coincide con el arzobispado de Diego de Deza, tutor del príncipe Juan y confesor de Fernando el Católico. Gracias al arzobispo, a quien el Cura de los Palacios sirve como capellán, llega a tener acceso a documentos y epístolas que incluye en su texto - como la correspondencia de Fernando y el Diario de Colón- y que hacen de sus Memorias una obra única. Sin embargo, el cronista oficial nombrado por Isabel era Hernando del Pulgar. Él será su modelo de cronista: lo sigue en la disposición de la materia narrada -al menos en sus primeros 100 capítulos, puesto que Pulgar sólo cubre el reinado hasta 1490- y llega a transcribir de él pasajes completos: se sirve no sólo de sus Letras sino que comenzará sus Memorias con una semblanza tomada de Claros Varones de Castilla, la de Enrique IV, texto pedido al Pulgar por Isabel que circuló impreso alrededor del 1500. Pareciera que la utiliza como auctoritas -y para introducir el estilo del que se valdrá-, para luego ampliarla en los capítulos subsiguientes, sea reponiendo sus omisiones -Juana la Beltraneja-, sea puntualizando aún más la negligencia del rey o deteniéndose más en las parcialidades de su gobierno.

Comencemos notando que en su semblanza Pulgar omite a la figura controvertida de Juana deliberadamente, puesto que amenaza la legitimidad de la reina $^{4}$, mientras que Bernáldez, que escribe una vez muerta Isabel y parecería ser «cronista» fernandino ${ }^{5}$, la incluye varios capítulos adelante con un propósito claro: incluir con ella a su madre y sus «andanzas» y rebajar aún más la figura de su predecesor. El pasaje reza así:

Ya es dicho $[\ldots]$ como en su segunda mujer manifestó su impotencia, por lo cual ella se dio a mal recabdo; e fue fama pública que se empreñó de un caballero, el

\footnotetext{
${ }^{3}$ Según los términos a quo muy bien señalados por Gómez-Moreno y Carriazo (Bernáldez, Andrés, Memorias del Reinado de los Reyes Católicos, ed. de Gómez-Moreno y Mata Carriazo, Madrid, Real Academia de la Historia,1962, pp. lix-lxii). Todas las citas de las Memorias de aquí en más responden a esta edición. En adelante se consigna la página entre paréntesis; las negritas son siempre nuestras.

${ }^{4}$ Isabel, hermana de Enrique, accede al trono luego de un conflicto sucesorio grave entre los partidarios de Juana como heredera legítima del trono, y aquellos que aducían su bastardía.

${ }^{5}$ Aunque Gómez-Moreno y Carriazo (ed. cit., p. lxiv) señalan que compuso la obra sin encargo oficial ni propósito de ensalzamiento de tal o cual personaje sino haciéndose eco de la opinión pública, consideramos que en el trabajo de selección y recopilación histórica, tanto de las fuentes como de los acontecimientos, se evidencia una fuerte tendencia a ensalzar y justificar tanto al rey como a su política. Aclaremos, igualmente, que dado el género híbrido del texto tal vez sea mejor llamarlo «historiador» fernandino, pero conservamos el de «cronista» para evitar caer en discusiones sobre la adscripción genérica de las Memorias, que merecería todo un trabajo aparte.
} 
más privado del rey su marido, e parió una hija a quien llamaron doña Juana, la cual siempre se crió con la sospecha de no ser hija del rey [...] e assí lo hizieron pregonar por toda Castilla [...]. E afirmando esto la dicha reina doña Juana [...] dióse muy mal exenplo, ca se empreñó e parió dos fijos de otro caballero de sangre real[...] e esto parece que lo causó la desventura del rey su marido, por no poder aver acesso a ella, e por no ser celoso de su casa e honrra. $\mathrm{Ca}$ muchas veces acaece a muy nobles dueñas pecar [...] de ser forçadas o tomadas la primera vez en lugar donde no se pueden defender, y por conservar su honrra callan; e a esto dan cabsa los maridos o padres [...] que se confían, no mirando de quién ni cómo, ca saludable cosa es a los hombres de buen juicio ser celosos e recelosos. (27-8)

El desorden en el que incurre la reina a causa de Enrique refleja y recalca, en el ámbito privado, la misma negligencia que el rey mostraría para con sus privados y su reino:

[...] como porque se deve creer que Dios punió en esta vida la desobediencia que este rey demostró al rey su padre, dio lugar a que fuese desobedecido de los suyos y permitió que, algunos criados [...] no pudiendo refrenar la envidia concebida de otros que pensaban ocuparles el lugar [...] y conocidas en este rey algunas flaquezas nacidas del hábito que tenía hecho en los deleites, osaron desobedecerle y poner disensión en su casa. La cual, porque al principio no fue castigada según debía, creció en ellos tanto que hizo decrecer el estado del rey y el temor y obediencia que los grandes de sus reinos le avían.[...] En esta división se despertó la codicia y creció la avaricia, cayó la justicia y señoreó la fuerza, reinó la rapiña, [etc][...]. Y Nuestro Señor, que algunas veces permite males [...] para que cada uno sea punido particularmente, según la medida de su yerro, permitió que oviese tantas guerras en el reino [...]. (7-8)

Pintado este panorama, Bernáldez introduce el cantar profético «que Dios [...] púsole en voces de niños sin pecado para hablar en señal de batalla con pendones» anunciando la llegada de un pendón de Aragón «antes que remediasse y destruyesse lo que a Castilla destruía y afligía» (21). La amplificatio de la semblanza revela ser la antesala perfecta para introducir la figura mesiánica de Fernando.

Como explicitan los fragmentos previos, no sólo las Memorias sino toda la producción historiográfíca del periodo se traza de acuerdo a un modelo de causa y efecto movido por la mano divina que, siguiendo a Tate ${ }^{6}$, dota a la monarquía de un aire de continuidad y permanencia que sus orígenes inmediatos

${ }^{6}$ Tate, ob. cit., p. 282. 
parecían negarle. Dios introduce su mano en la historia premiando o castigando; mano que, a la vez que desestima a Enrique, legitima a los nuevos reyes. La concepción agustiniana de la historia en el seno de un ambiente con conflictos sucesorios y de legitimidad, más que un discurso teológico que explica el devenir histórico, deviene un discurso político, al igual que el mesianismo. Providencialismo y mesianismo, de hecho, serán dos caras de una misma moneda.

En términos de recepción, frente a la incapacidad de argumentos lógicos que expliquen la nueva realidad que sobreviene con los Reyes Católicos, el providencialismo era una clave explicativa posible:

Los Reyes Católicos venían a interrumpir un período de anarquía y desquiciamiento general. Muchas cosas importantes peligraron en el reinado del último Enrique [...]. [Ahora] España sale del desorden y se lanza en una gran política en el espacio de pocos años, dentro de una misma generación [...]. Los hombres están acostumbrados a ver que los cambios exigen tiempo [...] pero aquellos españoles contemplaron el acelerarse de la historia hasta límites fuera de lo humano. Su lógica les falló. Su mente no podía comprender el fenómeno que se desarrollaba ante ellos y hubieron de atribuirle una razón Providencial. ${ }^{7}$

El ambiente es propicio, pues, para que el discurso providencialista se refuncionalice, y se vuelva una de las características principales de la producción cronística del período.

Ahora bien, aunque la obra de Bernáldez ha pasado a la historia como crónica, trasciende este género. Según los editores el título que le da el autor («yo, el que estos capítulos de Memorias escriví», 23) ampara cierta nota de discontinuidad en la narración, dando cabida a la anécdota, las curiosidades. Nos atreveríamos a decir, además, que escudarse en esta dimensión del «memorialismo» le permite incluir en su obra sin problema una vasta gama de géneros narrativos ${ }^{8}$, configurándose, así, una amplia estructura cronística. En cuanto a la intención de las Memorias, las razones que movieron a Bernáldez para registrar los hechos del pasado son poco ordinarias: fue movido por la curiosidad y el mandato de su abuela9 ${ }^{9}$, cuyo discurso utiliza tópicos

\footnotetext{
${ }^{7}$ Cepeda Adán, art. cit., p. 178.

${ }^{8}$ Se puede mencionar, sólo para poner dos ejemplos, que la conquista de Granada es narrada en términos de un relato épico-caballeresco y los viajes de Colón, a modo de relato de viajes. Epístolas, relatos épicos, registros necrológicos, todo encuentra cabida dentro de la dimensión memorialista.

${ }^{9}$ «Yo [...] seyendo de doce años, leyendo un registro de mi difunto abuelo, que fue escribano público [...] donde yo nací, hallé unos capítulos de algunas cosas haçañosas que en su tiempo avían acaescido, y oyéndomelas leer mi abuela viuda, su muger, siendo en casi senectud, me dixo: - Hijo, ¿y porqué no escribes así [...] las cosas buenas que en tus días acaescieren [?], por que las sepan los que después vinieren, y maravillándose desque las lean, den gracias a Dios». (23)
} 
comunes a los prólogos cronísticos y, por tanto, se presenta como la voz de la «historia». Más allá de esta anécdota familiar difícil de probar, en la voz del Bernáldez joven que se inserta a continuación se advierte que parece moverse por un objetivo claro: «Dixe muchas veces entre mí: "[...] escribiré hasta que vea el reino de Granada ser ganado de cristianos". E siempre tuve la esperanza de lo ver, e lo vi [...]» (23). Sus palabras hacen eco de toda una tradición profética que, ya desde tiempos tempranos, anunciaba la culminación de la reconquista y la restauración de la herencia visigótica, y que en época de Fernando pasó a ser asociada a su figura. No en vano, en este mismo capítulo -titulado «Del pronóstico del reinado del rey don Fernando el Católico»- es donde se introduce el cantar profético mencionado anteriormente. Bernáldez va a narrar, entonces, sobre los tiempos en los que sucede la tan esperada conquista de Granada; es el que narrará todo lo que se «cumple» en este reinado -empresas suspendidas o nunca soñadas, la reconquista, la unidad-y la «edad de oro» que comienza con los Reyes Católicos.

\section{Providencialismo y legitimación}

Con esta intención, pues, va a organizar su «crónica» alrededor de grandes núcleos narrativos, de los cuales tres son los que más sustentan la dimensión providencialista del relato: la conquista de Granada, el descubrimiento de América y la Inquisición y expulsión de los judíos. El género memoria, sin embargo, le permitirá incluir, como ya mencionamos, algunas digresiones o recuerdos anecdóticos que, en realidad, resultan siempre bastante estratégicos. Veamos sólo un ejemplo:

Luego del episodio de los moros en Málaga, encontramos una pequeña digressio (caps. LXIV-LXVI) que corresponde a una secuencia presente también en la Crónica de Pulgar: la Conquista de las Islas Canarias. Sin embargo, lo que él resuelve en una treintena de líneas, para Bernáldez serán tres capítulos narrados al estilo de un libro de viajes: describe cada isla, su geografía y beneficios económicos, los habitantes, su religión y costumbres, las mirabilia -gente que bebe agua de árboles que sudan, por ejemplo (137)La inserción de estos capítulos que funcionan casi como un relato autónomo, parecería «anecdótica» y tal vez un simple divertimiento retórico de amplificatio, pero veremos que tendrá una funcionalidad importante. Al final del primer capítulo de los tres, luego de una vasta descripción, dirá:

Fue preguntado a los ancianos de Gran Canaria si tenían alguna memoria de su nacimiento, o de quién los dexó allí, y respondieron: 
-Nuestros antepassados nos dixeron, que Dios nos puso e dexó aquí e olvidónos; e dixéronos, que por la vía de tal parte se nos abriría e mostraría un ojo o luz por donde viésemos.

Y señalaban hacia España, que por allí avían de ver e se les avía de abrir ojo por donde avían de ver. (139)

La profecía se introduce, esta vez, no ya a través de la voz del historiador que explica los hechos, sino de la de los mismos nativos, luego sojuzgados. Es su voz la que se hace cargo del mesianismo. La conquista no sólo entra así dentro del plan divino sino que se presenta como aquello esperado por los habitantes del lugar: España abre los ojos, trae luz. Insertado en el medio de la conquista de Granada, este relato justifica sutilmente la política de conquista fernandina, que aunque en el caso de Granada estaba más que justificada, no lo estará tanto en otros casos. El providencialismo mesiánico contribuye también, como vemos, a dotar a este tiempo y a la tierra española de un aura particular. En términos de Tate ${ }^{10}$, se reelaboran los acontecimientos recientes y lejanos «en vista de una perspectiva más amplia de misión espiritual y temporal de su país».

Volviendo a los ejes que sustentan la dimensión providencialista, nos detendremos sólo en algunas cuestiones de cada uno. En la conquista de Granada, la participación de Isabel será breve, pero elocuente. Cuando los acontecimientos están por precipitarse la reina manda al duque de Cádiz «que no oviesse escaramuça con los moros porque no muriesse gente e que le escusasse cuanto pudiese» empero el duque «n[o] se pudo guardar el mando de la reina» (2267). La batalla comienza en las puertas de la ciudad «e la reina e la infanta cuando vieron pelear, se hincaron de rodillas rogando a Dios nuestro Señor que quisiese guardar a los cristianos[...] e non ovo allí caballero cristiano [...] que no fincase su lança en moro; e non ovo dapño en los cristianos» (227). El pedido de Isabel da el puntapié para que intervenga la providencia, demostrándonos a su vez la especial relación del monarca con la misma. El mesianismo político resulta definido y configurado, pues, por esa efectiva intervención providencial. Al final del episodio, con la introducción de su voz el historiador hará bandera explícita del providencialismo: «E así dieron gloriosa fin a su santa y loable conquista, e vieron sus ojos lo que muchos reyes e príncipes desearon ver: un reino de tantas cibdades [...] ganado en diez años. ¡Qué fue esto sino que Dios quiso proveerlo dello e darlo en sus manos!» (233). Se cumple finalmente la empresa tan esperada: mesianismo y providencialismo se enlazan. Vimos, sin embargo, que lo que funciona en el relato es una providencia motivada, que no interviene de por sí sino que premia o castiga el accionar

${ }^{10}$ Tate, ob. cit., p. 282. 
humano. Este premio de Dios dotaría todas las acciones monárquicas previas de un aura ejemplar e incuestionable, que contrapone a los Reyes Católicos a Enrique, legitimando no sólo su derecho al trono sino su política.

En cuanto al segundo eje, los viajes colombinos, es bien sabido que en ellos se encuentran todos los mismos procedimientos que en su Diario: la descripción, la maravilla, lo hiperbólico, la presencia del oro. Sólo diremos, entonces, que lo que llama la atención en este caso es que el único personaje sea Colón. Todos los otros navegantes que lo acompañaban desaparecen muy sutilmente y así Bernáldez impone la figura del «descubridor», que se nos presenta como el instrumento de Dios y de los reyes en el cumplimiento de una empresa nunca soñada: el mandato de los monarcas lo postula como «enviado» y le confiere a su descubrimiento acentos de misión: «el rey y la reina [...] lo enbiaron en el nombre de Dios a descubrir»(271); luego lo vemos entrar a Sevilla «con mucha honra [...] el domingo de Ramos » (278). Estando en América, es Dios el que inspira sus acciones: «Mas Nuestro Señor, que siempre acorre a los humillados e de buena voluntad, les puso esfuerço, e puso en coraçón al Almirante que seguiese adelante» (320). En fin, mientras se presenta a los portugueses como aquellos que siempre intentaron y nunca pudieron descubrir tierras en esa dirección, la empresa española es otro premio providencial: «Y la buena ventura del rey y la reina e su merescer, quiso Dios que en su tiempo e días se hallase, e la fallasen e descubriesen ellos» (271). Así, tanto Colón como la empresa en sí, adquieren tintes providencialista-mesiánicos que contribuyen, nuevamente, a construir estos tiempos como época dorada.

Dada la especial atención que recibirá el tercer eje en el próximo apartado, nos detendremos ahora en un elemento particular de las Memorias: los grandes portentos. El primero que presenta el texto será un eclipse: luego del nacimiento y presentación a Dios del príncipe Juan (caps. XXXII y XXXIII) se introduce un capítulo pequeño, de no más de diez líneas, intitulado: «del espantoso eclipse que el sol hizo». Parecería ser algo anecdótico: viene narrando una secuencia de hechos y de repente interrumpe, casi sin ningún criterio de ilación ni con lo anterior ni con lo subsiguiente, con un hecho portentoso. Parecería, pues, un suceso que la memoria simplemente recuerda como acaecido durante ese año. Este es el caso de otro pequeño capítulo, el CCXVIII: en el medio de toda una sección sobre el cisma contra el Papa Julio y las disensiones de Luis XII, una monja pare un monstruo. El texto sigue adelante cómodamente, como si hubiera sido sólo una anécdota. Pero unos capítulos más adelante en Ravena será la gran batalla donde los españoles y el Papa son derrotados por Luis. Los portentos presagian, como vemos, grandes acontecimientos. Al final del texto, en el episodio del rey Manfredo, se explicita 
cómo funciona esta estrategia: antes de la muerte de los franceses invasores se captura un pez con forma de león y Bernáldez explica la relación entre ambos sucesos así: «De la cual crueldad e muerte de los franceses, antes que fuese fecha, fue vista una terrible señal en profeçía, ansí como algunas vezes vemos antes que venga alguna persecución o pestilencia, o muerte de rey, que vemos cometas o estrellas de ramos, o otras señales» ( 464). El eclipse anunciaría lo que ocurre ya muy avanzado el relato (cap. CLV): la trágica muerte de Juan.

El portento más importante, sin embargo, será el que precede la muerte de Isabel, del cual se dirá:

E ansí como en la muerte del enperador Carlos Magno [...] quiso Dios [...] que se mostrasen señales en su señorío e inperio e reinos del dolor de su muerte $[\ldots]$ Ansí paresçió que quiso [...] mostrar señales antes de la muerte desta tan exçelente y noble y neçesaria reina (488).

Será interesante señalar que en la tradición literaria contemporánea a Bernáldez -sea en las crónicas, en los relatos caballerescos o en la hagiografíadifícilmente se encuentren grandes portentos, sino sólo agüeros, milagros, etc. La presencia de prodigia es en realidad un motivo narrativo clásico ya presente en Tito Livio, Cicerón, Salustio, Tácito, Suetonio, sea para anunciar grandes batallas, sea para presagiar muertes de emperadores. Toda esta tradición historiográfica clásica, como sabemos, es retomada y cristianizada por Orosio $^{11}$, quien clasifica los portentos y resignifica la historia romana interpretándolos desde el Providencialismo: son manifestaciones divinas. Entre todos los que enumera, señala como los más importantes a los signa que presagian la llegada de Augusto, su Imperio y la pax romana -que anuncian a su vez la llegada de Cristo-, y los que ocurren durante su mismo Imperio, en el que las manifestaciones divinas se relacionan con el progreso del cristianismo.

Aquí se hace evidente pues, como, «la anécdota» está cargada de sentido. $\mathrm{La}$ «memoria» del historiador recuerda y selecciona eventos a los que carga de una significación de acuerdo a la tradición clásica que le son muy funcionales en relación a su «designio unificado del pasado». Los presagios unen pues, la historia hispánica a la romana, comparación que se hace explícita sólo unos párrafos después:

\footnotetext{
${ }^{11}$ Para una visión más profunda del tema véase Pedro Martinez Cavero, «Signos y Prodigios. Continuidad e inflexión en el pensamiento de Orosio», Antig. crist., 14 (1997), pp. 83-95, quien hace un muy buen análisis de la relación entre el motivo clásico del presagio y la reapropiación orosiana. Para una introducción al pensamiento orasiano en general véase Serafín Bodelón, «Orosio: una filosofía de la historia», en Memorias de Historia Antigua, 18 (1997), pp. 59-80.
} 
Ansí como Roma en su imperio floreció en tiempos del emperador Otaviano Augusto, que fue en tienpo del nasçimiento del Nuestro Redenptor [...] e fueron numeradas e obedientes a su imperio en aquel tiempo noventa mil trezientas çibdades[...] e los tuvo todo en paz e obediencia [...] e Roma fue entonçe más triunfante que antes ni después, ansí España fue en tienpo destos bienaventurados rey y reina don Fernando y doña Isabel [...] más triunfante e más sublimada, poderosa, temida y onrrada que nunca fue.(489)

Bernáldez, pues, no hace más que construir una España similar a aquella Roma que esperaba la llegada de Augusto, el que finalmente establece la pax romana y el Imperio, período en el cual nacería Cristo. Se construye, así, la idea de una pax hispanica, del Imperio y la Edad Dorada. Una verdadera propaganda histórica escrita y divulgada en tiempos en los que el rey necesita legitimarse frente a los partidarios de su hija, la reina Juana la Loca, encerrada en Tordesillas.

\section{Providencialismo e inflexión: la Inquisición en Bernáldez y Pulgar}

Ahora sí nos detendremos en el tercer eje. Las estrategias discursivas que logran que este conjunto de cruentos hechos quede justificado en las Memorias y más aún, sea el mayor acierto del reinado, son de lo más variadas. La que más sobresale es, claro, el discurso providencialista, que llega en este episodio a su culmen y mayor desarrollo.

Comienza Bernáldez la descripción de los judíos ${ }^{12}$ con una cita en latín del Apocalipsis 13 que traducirá a continuación: «O bestia fiera malvada, disforme pecado, nudrimiento de traición, hallamiento de muerte, perdimiento de vida» (96). Las imágenes que se les asigna serán también elocuentes: «hediondos judíos [...] por causa de los manjares y de no ser bautizados [...] comilones», hedor que ayuda a identificar, incluso, a los conversos. No será casual, pues, que en el capítulo siguiente se mencione la epidemia que acechó a Sevilla mientras actuaba la Inquisición, puesto que el hedor figuraba entre una de las causas de su propagación ${ }^{13}$. Además, el hedor estaba en el Medio-

\footnotetext{
${ }^{12}$ Para un primer acercamiento al tratamiento de los judíos en la literatura medieval castellana resultan de utilidad los artículos de Seymour Resnick, «The Jew as Portrayed in Early Spanish Literature», en Hispania 34 (1951), pp. 54-58 y de Eleazar Gutwirth, «The jews in $15^{\text {th }}$ Century castilian chronicles», en The Jewish Quarterly Review, 74:4 (1984), pp. 379-96. Véase especialmente también E. Michael Gerli, «Social Crisis and Conversion: Apostasy and Inquisition in the Chronicles of Fernando de Pulgar and Andrés Bernáldez» in Hispanic Review 70:2 (2002), pp. 147-167, el cual nos ha servido para trazar los primeros lineamientos de este trabajo.

${ }^{13}$ «Porque en los tiempos que ay corrupción en el ayre, la qual haze pestilencia en los cuerpos humanos e mantenimientos [...]» (Fernando Álvarez, Regimiento contra la peste en Tratados de la peste de Velasco de Taranta, Licenciado Flores, Fernando Álvarez y Diego Álvarez Chanca, ed. de María Nieves, Madrid, Arco Libros, 1993, pp. 160-175, cita en pp. 9-10); "Quiero esso mismo que sepas que
} 
evo relacionado con el diablo ${ }^{14}$. Los judíos, implícitamente, son causa de la pestilencia y se nos presentan, pues, cercanos al diablo, origen de pecado y enfermedades. Se detendrá inmediatamente en su usura, notando cómo la justifican por el mandato divino: «allegaron muy grandes caudales e haciendas, porque de $[\ldots]$ usura no hacían conciencia, diciendo que lo ganavan con sus enemigos, atándose al dicho que Dios mandó en la salida del pueblo de Israel robar a Egipto por arte e engaño» (98) y luego, cuando huyen a Portugal, en su simple codicia: «es verdad que sacaron infinito oro e plata escondidamente $[\ldots]$ en los vientres» (256). Frente al primer accionar de la Inquisición, Bernáldez señala cómo «ellos tenían que los cristianos eran los egipcianos, e peores, e creían que Dios milagrosamente los sostenía [...] e que por mano de Dios avían de ser acaudillados [...] e llevados a la sancta tierra de promisión» (102). La relación España-Egipto en el seno del discurso hebraico establece una conexión tipológica con el Éxodo que llega a su culmen cuando huyen a Portugal: sus rabíes les decían:

[...] que aquello venía por Dios, que los quería sacar de cabtivos y llevar a la tierra de promisión e que en esta salida verían cómo Dios haría por ellos muchos milagros $[\ldots]$ y que si $[\ldots]$ oviesen alguna fortuna o siniestro, que entrando en el mar verían cómo Dios sería su guiador, como avía fecho con sus antepasados en Egipto. (253-4)

Sin embargo, los judíos ya llegados a Fez son despojados, violados, asesinados y retornan a España recitando los pasajes proféticos de Isaías $\mathrm{X}$-que anuncian la llegada del salvador-, asegurando que creen que se han cumplido. Y agrega: «E con esto, desque vían acá, daban muchos loores a Dios, que los avía sacado de entre las bestias brutas e traído a tierra e gentes de razón» (261). Vemos que Bernáldez se hizo cargo de la conexión tipológica irónicamente, para poner en jaque al discurso providencialista judaico y subvertirlo. Construye, en realidad, una inversión tipológica: aquella tierra de la que huyen y a la que finalmente vuelven se acerca más a la Tierra de promisión que a Egipto. El episodio se cerrará con el propio Bernáldez citando la palabra divina que, a través de la profecía de David, señala que lo predicho se ha cumplido: «E aquí paresce que se cunplió la profecía que dixo David [...] que dize: [...] Convertirse han a la tarde, y abrán hanbre como perros, e andarán

en el tiempo de la peste aquellos mueren antes en cuyas casas hay fedores particulares [...] e la causa desto es porque la corrupción del aire vniversal se multiplica e se enfortece por el particular.» (Velasco de Taranta ,Tratados de la peste, en ed. cit., pp. 158-166).

${ }^{14}$ En los Milagros de Nuestra Señora, por ejemplo, se designa al Infierno como «logar fediendo», y a sus habitantes como «fedionda cofradía». (802c) 
cercando la cibdad» (262). A través de referencias y citas del Apocalipsis y el Antiguo Testamento, se configura la trama narrativa a través de la cual la Inquisición cobra sentido en la Palabra de Dios, formando una parte esencial -culminativa se podría decir- de la historia divina. A su vez, se desplaza al pueblo judío de su lugar de elegido a través de la puesta en jaque de su discurso. Todo lo sucedido será una prueba fehaciente, y la más lograda, de la misión mesiánica de los monarcas.

El cronista oficial dará, sin embargo, una visión bastante particular de estos sucesos (caps. XCVI y CXX). Es bien sabida, de hecho, la condición conversa de Pulgar ${ }^{15}$. Antes de adentrarnos en el episodio, notemos cómo en toda su crónica, otro fiel ejemplar del ambiente providencialista del momento, la «mano divina» se inmiscuye en todos los acontecimientos, moviendo los hilos de la Historia. Sólo un ejemplo:

Averse ganado esta villa en tan poco espacio de tiempo [...], syn dubda se puede decir cosa digna de admiración más que cosa guiada por razón. Porque aquellos tiros que los quartados facían eran ynciertos, y vezes davan en el çircuyto de las villas, veces fuera dellas. E porque plogo a Dios quel primero tiro que disparó un quartado açertase en aquel pequeño lugar, pareçió ser cosa fecha por mano de la divina Providençia, porque se oviese aquella villa que en largo tiempo y con mucho gasto y pérdida de gente no se esperaba aver. $(235)^{16}$

En los dos capítulos sobre la Inquisición, en cambio, las causas del devenir parecen ser otras. Por un lado, la prolífica sucesión de acontecimientos sin hilo pareciera mostrarnos los hechos tal cual son, efecto logrado por la acumulación paratáctica. Veamos:

E si algunos había culpados en aquel crimen [...] luego eran presos, e se facían procesos contra ellos, por virtud de los cuales eran condenados por hereges e apóstatas [...]. Déstos fueron quemados [...] fasta dos mil homes e mugeres; e otros fueron condenados a cárcel perpetua; e a otros fue dado por penitencia que todos los días de su vida andoviesen señalados con cruces grandes coloradas [...]. E los inhabilitaron [...] de todo oficio público que fuese de confianza.[...]. Ansimesmo se facía inquisición si los que eran

\footnotetext{
${ }^{15}$ Además de la carta dada a conocer por Mata Carriazo (Fernando del Pulgar, Crónica de los Reyes Católicos, ed. de Mata Carriazo, Madrid, Espasa Calpe, 1946, V, pp. xxxviii-xxxix) en la que el cronista abiertamente expone sus discrepancias con la política inquisitorial y que le habría costado el alejamiento de la corte, la tesis de Pontón Gijón (Pontón Gijón, Gonzalo, La obra de Fernando del Pulgar en su contexto histórico y literario, tesis doctoral en microfichas, Bellaterra, 1999, pp. 20-2) habría probado sobradamente su condición judeo converso poniendo punto final al debate.

${ }^{16}$ Todas las citas de las Crónica de los Reyes Católicos corresponden a la edición de Mata Carriazo (ob. cit.). En adelante se consigna la página entre paréntesis. Las negritas serán siempre nuestras.
} 
muertos dentro de cierto tiempo habían judaizado [...] e fueron condemnados e sacados sus huesos de las sepulturas, e quemados públicamente; e inhabilitaron a sus fijos para que no oviesen oficios ni beneficios. Déstos fue fallado gran número, cuyos bienes y heredamientos fueron tomados e aplicados al fisco del Rey e de la Reyna. [...] [M]uchos de los de aquel linage, temiendo aquellas execusiones, desampararon sus casas e bienes, e se fueron al reyno de Portugal $[\ldots]$ e les eran tomados sus bienes, de los quales, e de las penas pecunarias que pagaban los reconciliados [...] mandaron el Rey e la Reyna que no se distribuyesen en otra cosa, salvo en la guerra contra los moros, o en otras cosas que fuesen para el ensalzamiento de la fé católica. Algunos parientes de los presos e condemnados reclamaron, diciendo que aquella inquisición y execución era muy rigurosa $[. .$.$] e que en la manera que se tenía$ en el facer de los procesos y en la execución [...] los executores mostraban tener odio a aquellas gentes. [...] E como quier que la absencia de esta gente despobló gran parte de aquella tierra, e fue notificado a la Reyna que el trato se disminuía; pero [...], decía que todo interese pospuesto quería alimpiar las tierras de aquel pecado de la heregía, porque entendía que aquello era servicio de Dios e suyo. E las suplicaciones que le fueron fechas en este caso, no la retraxeron deste propósito. (337)

Desde esta perspectiva de observación inmediata logra que el ojo se centre en la irracionalidad y crueldad de los sucesos que parecen no tener otra causa más que el «pesar [del Rey e la Reyna] por se fallar en su señorío personas que no sintiesen bien de la fé católica» (334). Persecución, humillación, marginación laboral, profanación de tumbas, expropiación. De manera muy disfrazada, en el medio de esta pintura casi realista, se insinúan causas no movidas por la fe, sino económico-sociales ${ }^{17}$ : acrecentar el fisco de los monarcas y así solventar la guerra. Por el otro, introduce la voz de los familiares que se quejan puntualizando el odio y las malas maneras, incitando sospechas sobre las figuras inquisitoriales. De hecho, estas voces hacen hincapié en cómo debería ser el accionar de la Iglesia, resaltando la contradicción entre doctrina y práctica:

E que considerada la piedad de Dios y lo que la Santa Madre Iglesia manda vsar en este caso, con dulces raçones y blandas amonestaciones [...] se debían traer a la Fé a aquellos errados. E siguiendo los preçebtos y reglas de los santos cánones, los debían reducir e admitir en las penas que las leyes disponen, e no con aquella cruel pena del fuego (440).

Luego, como vimos, se relatan las consecuencias nefastas que en realidad la expulsión ha acarreado en lo económico y se muestra a una Isabel pertinaz

${ }^{17}$ Véase Gerli, art. cit., p. 157. 
en la inquisición ya que «entendía que aquello era servicio de Dios e suyo».

Evidentemente el cronista oficial no puede demostrar abiertamente su indignación -hacerlo ya lo había obligado a alejarse de la corte entre $1480 \mathrm{y}$ 1482 (ver nota 15)- y se sirve, por tanto, de varias estrategias. En principio, se deshace del recurso retórico del discurso providencial y presenta los hechos tal cual son, con sus causas y consecuencias verdaderas. Introduce, además, críticas veladas y repite en los dos episodios el contraste de las atrocidades que narra con la escena final de Isabel asegurando que hace todo por Dios. El resultado es irónico, acentuado no sólo por el contraste entre el discurso de Isabel y los hechos tal como nos los mostró Pulgar, sino también por el contraste entre este episodio y cómo ha venido construyendo toda la crónica: Dios aquí no está. La conciencia historiográfica del cronista, involucrado afectivamente en estos sucesos, no logra aprehender esta realidad de acuerdo a los parámetros culturales característicos: el discurso providencialista ya no sirve para explicar estos hechos. Así, la conciencia historiográfica típica que legitima, conscientemente o no, a la monarquía por unos pasajes se suspende. En conclusión, vemos cómo comienza a surgir la conciencia de una Historia que se lleva a cabo en nombre de Dios, pero de la que Dios ha sacado la mano ${ }^{18}$. La Inquisición estará lejos de formar parte del plan divino.

\section{La puesta en jaque al providencialismo: Bartolomé de Las Casas}

El tratamiento que Pulgar da a los hechos inquisitoriales será similar al que, unas décadas después y desde tierra americana, Las Casas utilice para defender a los indios ${ }^{19}$ e impulsar la promulgación de las Leyes Nuevas. Tengamos en cuenta que, como ya dijimos, las Crónicas de Indias, en cuanto herederas de la historiografía española, se configuran dentro de los mismos parámetros discursivos: Cortés, por ejemplo, se sirve del discurso providencialista para justificar su rebelión ${ }^{20}$; el Inca Garcilaso, desde una perspectiva

\footnotetext{
${ }^{18}$ Cfr. Gerli, art. cit. p. 163.

${ }^{19}$ Las Casas escribe en 1542 la Brevísima relación de la destrucción de las Indias, con la intención de que sea más apropiada para la lectura de Felipe II de lo que, por su vasta extensión, su Historia de las Indias y la Apologética Hitoria habían sido para Carlos V, cuyas denuncias desatendió. Para un análisis detallado de las intenciones políticas que mueven al fraile ver Juan Friede, Bartolomé de las Casas: precursor del anticolonialismo, México, Siglo XXI Editores, 1974.

${ }^{20}$ En la «Introducción» a Crónicas de Indias Mercedes Serna dirá respecto de Cortés que «El primer proceso de ficcionalización a lo largo de las tres primeras cartas busca convertir su rebelión en servicio a la corona. [...] El providencialismo [...] le sirve, en esta estructura ficcional, para presentar a Dios como aliado suyo frente a los aztecas y los seguidores de Velázquez y santificar su empresa. El rebelde se transforma en héroe [...]» (Mercedes Serna, Crónicas de indias: una antología, Madrid, Cátedra, p. 78).
} 
contraria, lo utiliza para justificar la importancia de la historia incaica ${ }^{21}$. La relación de Las Casas con este discurso será particular, sin embargo.

Si en el episodio de Pulgar teníamos una acumulación paratáctica de sucesos, en Las Casas este recurso será llevado al paroxismo y tendremos, en palabras de Beatriz Pastor, una «acumulación exhaustiva de horrores, [una] generalización sistemática de crueldades $»^{22}$ :

Entraban en los pueblos, ni dejaban niños, ni viejos, ni mujeres preñadas ni paridas que no desbarrigaban e hacían pedazos. [...] Hacían apuestas sobre quién de una cuchillada abría el hombre por medio, o le cortaba la cabeza de un piquete o le descubría las entrañas. Tomaban las criaturas de las tetas de las madres, por las piernas, y daban de cabeza con ellas en las peñas. Otros, daban con ellas en ríos por las espaldas, riendo e burlando; [...] otras criaturas metían a espada con las madres juntamente, e todos cuantos delante de sí hallaban. Hacían unas horcas largas, [...] e de trece en trece, a honor y reverencia de Nuestro Redemptor e de los doce apóstoles, poniéndoles leña e fuego, los quemaban vivos. (114)

Estas características no son, como se le ha imputado, signo de ineptitud expositiva, sino parte de toda una estrategia deliberada de desestabilización de la política y del discurso de los conquistadores. Así, no teme exponer explícitamente el motor de sus acciones:

La causa por que han muerto y destruido tantas y tales e tan infinito número de ánimas los cristianos ha sido solamente por tener por su fin último el oro y henchirse de riquezas en muy breves días e subir a estados muy altos e sin proporción de sus personas (conviene a saber): por la insaciable codicia e ambición que han tenido [...]. (111)

${ }^{21}$ Serna, en su edición a Comentario Reales, aclarará: «No sólo sustenta [el] autor la noción de providencialismo, sino que articula la idea de que los incas fueron los que prepararon el camino para el advenimiento de los españoles y, con ellos, del cristianismo. [...] La idea de la prefiguración del cristianismo le sirve al autor para explicar la historia de los incas, [...] e insertarlos en el mundo cristiano y para [...] incluirlos en la historia de Occidente» ( Garcilaso de la Vega, Comentarios reales, ed. de Mercedes Serna, Madrid, Castalia, 2000, pp. 61-4). Para un estudio más detallado ver Pierre Duviols, «Providencialismo histórico en los Comentarios Reales de los Incas y la Historia General del Perú del Inca Garcilaso de la Vega. Constatación e inventario», en Javier Flores Espinoza (ed.), El hombre y los Andes; homenaje a Franklin Pease, Lima, Pontificia Universidad Católica del Perú, 2002, I, pp. 397-408 y Enrique Moreno Báez, «El providencialismo del Inca Garcilaso», en Estudios Americanos, 35-36 (1954), pp. 143-154.

${ }^{22}$ Beatriz Pastor, «Utopía y Revolución», en su El jardín y el peregrino. El pensamiento utópico en América Latina (1492-1695), México, Difusión Cultural UNAM, 1999, cita en p. 251.

${ }^{23}$ Todas las citas de la Brevisima responden a la edición crítica de Martínez Torrejón (Casas, Bartolomé de las, Brevísima relación de la destruición de las Indias, ed. de José Miguel Martínez Torrejón, Alicante, Universidad, 2006). Se consignará a continuación el número de páginas entre paréntesis; las negritas, siempre nuestras. 
Como Pulgar, veíamos en el primer pasaje que Las Casas también contrasta el cruento accionar de los cristianos con su discurso religioso. Sin embargo, el dominico no se contenta sólo con esto. Más adelante en su relación, dirá:

Y los tristes ciegos, dejados de Dios venir a reprobado sentido, no viendo la justísima causa, y causas muchas llenas de toda justicia, que los indios tienen por ley natural, divina y humana de los hacer pedazos, [...] piensan y dicen y escriben que las victorias que han de los inocentes indios asolándolos, todas se las da Dios, porque sus guerras inicuas tienen justicia. (166)

Las Casas señala aquí la ceguedad en la interpretación de la realidad indiana, a la que se refiere a través de una enumeración gradual que acentúa el último término, la escritura. La ceguedad se enlaza, pues, con la escritura de la victoria, referencia evidente a las crónicas de Indias. Así, denuncia el error y el vacío del discurso providencialista del que se valen: Dios no es el que les da esas victorias, puesto que la «justísima causa» de vencer es de los indios. Aquí el discurso de Las Casas, además, confirma su esencia combativa: armado en base a la retórica jurídica introduce luego un contraste cruento - «los hacer pedazos»)-. La violencia parece justificarse en su bando. Asimismo, el vacío del providencialismo se señala mediante otra operación: el corrimiento del referente divino: «Comenzó a hacer las crueldades y maldades que solía, e que todos allá tienen de costumbre, e muchas más, por conseguir el fin que tienen por dios, que es el oro» (164). El dios que los mueve no es el Dios cristiano por el que dicen moverse sino el oro.

La mano divina, sin embargo, no está ausente de la Brevísima. Veamos algunos pasajes:

[Al rey Caonabó] prendieron con una gran sutileza y maldad [...]. Metiéronlo después en un navío para traello a Castilla, y estando en el puerto seis navíos para se partir, quiso Dios mostrar ser aquella con las otras grande iniquidad y injusticia y envió aquella noche una tormenta que hundió todos los navíos y ahogó todos los cristianos [...]. (118)

Dejaron toda la tierra escandalizada e puesta en la infamia y horror de su nombre con algunas matanzas que hicieron, pero no muchas, porque los mató Dios antes que más hiciesen, porque les tenía guardado para allí el castigo [...]. (198)

Una vez más, estamos delante de un Dios que mueve la Historia -causa tormentas, hunde barcos, mata gente- para demostrar su juicio: la conquista es «grande iniquidad e injusticia». El discurso providencialista, que las 
primeras crónicas de indias utilizan para justificar la conquista y obtener favores reales, en Las Casas se subvierte: Dios está del lado de los indios y, por tanto, de ese lado debe ubicarse el rey. Al final de la Brevísima hace esta apelación más explícita: no sólo despoblaron las Indias, sino que terminan matándose entre ellos «con justo juicio de Dios: que pues no ha habido justicia del rey que los castigue, viniese del cielo, permitiendo que unos fuesen de otros verdugos» (225). La justicia divina compensa la falta de acción judicial que el rey hasta ahora ha tenido y que, con esta estrategia, se está promoviendo. Al poner del lado de los indios al discurso providencialista, en realidad no está sólo justificando su guerra e impulsando su defensa, sino obligando al rey a que actúe y los juzgue desde «el juicio de Dios», el único que como rey puede tomar. Antes, claro, ha tenido que poner en jaque al discurso providencialista de las crónicas, a través de las cuales el rey había ido enterándose de los sucesos americanos.

Para concluir, algunas anotaciones. Por un lado, vimos cómo el discurso providencialista es efectivo a la hora de justificar y legitimar el devenir histórico. Por el otro, de los casos analizados se deriva cómo la tendencia es ponerlo en jaque cuando hay implicancias ideológico-políticas. Bernáldez subvierte el discurso providencialista judío -imputando su utilización tanto para justificar la actividad económica como para atenuar la realidad- para aplicarlo a los cristianos y justificar la política monárquica; Pulgar, en cambio, pone en jaque al discurso cristiano a través de voces judías pero por sobre todo con el silencio: ya no se siente la voz de Dios ni se ve su mano. Estamos delante de una conciencia histórica diferente, que percibe -aunque sea como intuición- el alcance ideológico del discurso y se sirve de ello. Las Casas hará de esta conciencia que observa un mundo llevado adelante en nombre de Dios pero sin Él, bandera política y estrategia principal que domine todo el relato. Acaso sea la paradójica relación con el otro y la paulatina conciencia de su otredad lo que impulse el cambio que se da en este aspecto del punto de vista historiográfico.

Recibido: 20/07/2011

Aceptado: 15/09/2011 
RESUMEN: Este trabajo, centrado en el análisis del discurso providencialista en las obras de Bernáldez, Pulgar y Las Casas, pretende ser un aporte al estudio de la evolución del género cronístico, especialmente a la paradigmática relación crónica regia-crónica de indias. Veremos, primero, cómo este discurso determina todas las estrategias narrativas y la elección aparentemente azarosa de la materia narrada. Analizaremos luego en La Crónica de Pulgar cómo este punto de vista historiográfico varía en un episodio -la Inquisición-, variación que se manifiesta como una de las primeras documentaciones de lo que sucederá más adelante con Las Casas. El trabajo nos llevará a probar cómo este discurso resulta efectivo a la hora de justificar y legitimar el devenir histórico, pero a la vez la tendencia comienza a ser ponerlo en jaque cuando hay implicancias ideológico-políticas. Estamos, tal vez, delante de una conciencia histórica diferente.

ABSTRACT: This paper, centered on the analysis of the providentialist discourse in the works of Bernáldez, Pulgar and Las Casas, is just a humble contribution to the study of the evolution of the chronistic genre, especially to the paradigmatic relation between royal chronicles and Indian chronicles. We shall see, firstly, how this discourse determines all the narrative strategies and the apparently random selection of the narrative material. We shall analyze then in Pulgar's Crónica how this historiographical point of view shifts in one episode -the inquisition-, shift that manifests itself as one of the first documentations of what will happen later with Las Casas. This paper will lead us to prove how this discourse is effective to justify and legitimize the course of history, but at the same time the tendency starts to be to put it in check when there are ideological and political implications. We are, may be, in front of a different historical conscience.

Palabras Clave: Providencialismo. Bernáldez. Pulgar. Las Casas. Crónica Regia y Crónica de Indias. Legitimación e inflexión del discurso.

Keywords: Providencialism. Bernáldez. Pulgar. Las Casas. Royal and Indian Chronicles. Legitimation and shift of the discourse. 
